\title{
Proteomic analysis of the excretory/secretory products and antigenic proteins of Echinococcus granulosus adult worms from infected dogs
}

\author{
Ying Wang ${ }^{1}$, Di Xiao ${ }^{2}$, Yujuan Shen ${ }^{1}$, Xiuming Han ${ }^{3}$, Fei Zhao ${ }^{2}$, Xiaohong Li', Weiping Wu' ${ }^{1}$, Hejun Zhou',
} Jianzhong Zhang ${ }^{2^{*}}$ and Jianping Cao ${ }^{1 *}$

\begin{abstract}
Background: Cystic echinococcosis, which is caused by Echinococcus granulosus, is one of the most widespread zoonotic helminth diseases that affects humans and livestock. Dogs, which harbor adult worms in their small intestines, are a pivotal source of E. granulosus infection in humans and domestic animals. Therefore, novel molecular approaches for the prevention and diagnosis of this parasite infection in dogs need to be developed.
\end{abstract}

Results: In this study, we performed proteomic analysis to identify excretory/secretory products (ES) and antigenic proteins of E. granulosus adult worms using two-dimensional electrophoresis, tandem matrix-assisted laser desorption/ ionization time-of-flight (MALDI-TOF/TOF), and Western blotting of sera from infected dogs. This study identified 33 ES product spots corresponding to 9 different proteins and 21 antigenic protein spots corresponding to 13 different proteins. Six antigenic proteins were identified for the first time.

Conclusions: The present study extended the existing proteomic data of E. granulosus and provides further information regarding host-parasite interactions and survival mechanisms. The results of this study contribute to vaccination and immunodiagnoses for $E$. granulosus infections.

Keywords: Echinococcus granulosus, Adult worm, Excretory/secretory products, Antigenic protein, 2-dimensional gel electrophoresis, MALDI-TOF/TOF

\section{Background}

Cystic echinococcosis (CE) is a type of zoonosis caused by Echinococcus granulosus, a canine tapeworm [1]. According to recent estimates, 4 million individuals are affected with $\mathrm{CE}$ and 40 million individuals are at risk [2-4]. The life cycle of E. granulosus is complex and involves two hosts: definitive and intermediate hosts. The definitive hosts are primarily dogs, which harbor adult worms in their small intestines. The intermediate hosts, e.g., humans and herbivores, particularly sheep and cattle, get infected

\footnotetext{
*Correspondence: zhangjianzhong@icdc.com; caojp@yahoo.com ${ }^{2}$ Collaborative Innovation Center for Diagnosis and Treatment of Infectious Diseases, State Key Laboratory for Infectious Disease Prevention and Control, National Institute for Communicable Disease Control and Prevention, Chinese Center for Disease Control and Prevention, Beijing 102206, China ${ }^{1}$ National Institute of Parasitic Diseases, Chinese Center for Disease Control and Prevention; Laboratory of Parasite and Vector Biology, MOH, China; WHO Collaborating Center for Malaria, Schistosomiasis and Filariasis, Shanghai 200025, China

Full list of author information is available at the end of the article
}

through the ingestion of parasite eggs released in the feces of definitive hosts or through consumption of foods contaminated with the parasite eggs [5]. Dogs, as definitive hosts, are therefore pivotal in the transmission of CE.

One of the strategies to reduce the risk of infection is to interrupt the transmission of CE. Vaccination of the definitive hosts is an effective method. As there are far fewer dogs than sheep and cattle in endemic areas, far fewer animals consequently need to be vaccinated. However, a limitation of vaccination is that the immune modulatory mechanisms of E. granulosus are not fully understood. The immune modulatory mechanisms of the parasite might involve antigenic proteins and excretory-secretory (ES) products released by the parasite [6,7]. The surveillance of $E$. granulosus infections in definitive hosts through sensitive diagnostic procedures is of paramount importance; coproantigen detection and arecoline purgation are not sufficiently sensitive. Therefore, there is an 
urgent need to identify immune markers that can be used in diagnosis and vaccine development. The identification of ES products and antigenic proteins could provide valuable insights into host-parasite interactions and improve the repertoire of candidate proteins used in immunodiagnoses, vaccination, and therapy. However, E. granulosus adult worms have received little attention; most studies have focused on the pre-adult stage of the parasite [8-11]. The proteomic profile of ES products and antigenic proteins from adult E. granulosus remain to be elucidated.

In this study, we investigated the ES products and antigenic proteins of E. granulosus adult worms from infected dogs using two-dimensional polyacrylamide gel electrophoresis (2DE) and tandem matrix-assisted laser desorption/ionization time-of-flight (MALDI-TOF/ TOF) mass spectroscopy. The results obtained from this study are crucial for understanding the survival mechanisms of E. granulosus and host-parasite interactions. Furthermore, the results could assist in the development of vaccine antigens, drug targets, and immunodiagnosis markers.

\section{Methods}

\section{Ethics statement}

This study was performd in strict accordance with the recommendations of the Guide for the Care and Use of Laboratory Animals of the National Institute of Parasitic Diseases, Chinese Center for Disease Control and Prevention. The protocol was approved by the Laboratory Animal Welfare \& Ethics Committee (LAWEC), National Institute of Parasitic Diseases, Chinese Center for Disease Control and Prevention (Permit Number: IPD 2010-007). Three dogs used in the research belonged to local farmers. The owners of the all dogs have oral consent for the use of their dogs in this research by explaining the purpose of the research and ensuring the welfare of animals.

\section{Collection and culture of parasites}

All dogs were infected with E. granulosus protoscoleces from sheep after dewormed with praziquantel, and sacrificed to obtain intestines at $40 \mathrm{~d}$ post-infection. All surgery was performed under sodium pentobarbital anesthesia, and all efforts were made to minimize suffering. Worms were released by soaking the intestinal contents in phosphate-buffered saline (PBS, Gibco, California, USA), washed in sterile PBS containing 100 $\mathrm{U} / \mathrm{ml}$ penicillin $\mathrm{G}$ and $100 \mu \mathrm{g} / \mathrm{ml}$ streptomycin (Gibco), and cultured for $24 \mathrm{~h}$ at $37{ }^{\circ} \mathrm{C}$ at 500 worms $/ \mathrm{ml}$ in serum-free RPMI 1640 medium (Gibco) supplemented with $2 \%$ glucose (Sigma, St.Louis, USA) and antibiotics. The supernatant was harvested and concentrated using a micro-concentrator with a 3-kDa cut-off (Millipore, Massachusetts, USA).

\section{Sample preparation}

The concentrated supernatant was precipitated overnight at $-20{ }^{\circ} \mathrm{C}$ with five volumes of ice-cold acetone containing $0.2 \%$ dithiothreitol (DTT; w/v) and $20 \%$ trichloroacetic acid $(\mathrm{TCA} ; \mathrm{w} / \mathrm{v})$. Protein precipitates were collected by centrifugation $\left(10,000 \mathrm{rpm}, 4{ }^{\circ} \mathrm{C}\right.$, $10 \mathrm{~min}$ ) and washed three times with ice-cold acetone containing $0.2 \%$ DTT $(\mathrm{w} / \mathrm{v})$. The resulting pellet was freeze-dried, suspended in lysate buffer (6 M urea, $2 \mathrm{M}$ thiourea, 4.0 \% CHARPS, $40 \mathrm{mM}$ DTT, and $0.5 \%$ IPG; $\mathrm{pH} 3-10$ ), and sonicated in ice until the suspension became clear. The homogenate was centrifuged at $12,000 \mathrm{rpm}$ for $15 \mathrm{~min}$ at $4{ }^{\circ} \mathrm{C}$. The resulting supernatant contained ES products.

E. granulosus adult worms were washed in PBS, suspended in lysate buffer, and sonicated in ice until the suspension became clear. The homogenate was centrifuged at $12,000 \mathrm{rpm}$ at $4{ }^{\circ} \mathrm{C}$ for $15 \mathrm{~min}$. The supernatant contained adult worms.

The samples were cleaned up using the 2D Clean-up kit (Amersham Biosciences), quantified using the 2D Quant Kit (Amersham Biosciences), and subjected to 2DE.

\section{Two-dimensional electrophoresis}

One-dimensional isoelectric focusing (IEF) and twodimensional sodium dodecyl sulfate polyacrylamide gel electrophoresis (SDS-PAGE) were performed (Amersham Biosciences). Briefly, $100 \mu \mathrm{g}$ of the ES sample in $130 \mu \mathrm{l}$ rehydration buffer was loaded onto a $7-\mathrm{cm}$ immobiline IPG drystrip (pH3-10NL; Amersham Biosciences); $800 \mu \mathrm{g}$ of adult worm protein sample in $450 \mu \mathrm{l}$ of rehydration buffer was loaded onto a 24-cm immobiline IPG drystrip (pH3-10NL; Amersham Biosciences). IEF was performed at 80,000 Vh using Ettan ${ }^{\mathrm{Tw}}$ IPGphorII (Amersham Biosciences). The drystrips were equilibrated twice (15 min each time) in equilibration buffer (50 mM Tris- $\mathrm{HCl}$ [pH 8.8], $6 \mathrm{M}$ urea, 30 \% glycerol, 2 $\%$ SDS, and $1 \%$ DTT for the first equilibration; $50 \mathrm{mM}$ Tris- $\mathrm{HCl}$ [pH 8.8], $6 \mathrm{M}$ urea, $30 \%$ glycerol, $2 \%$ SDS, and $4.8 \%$ iodacetamide for the second equilibration). Two-dimensional SDS-PAGE was performed on a $12 \%$ polyacrylamide gel in the Ettan ${ }^{\mathrm{TM}}$ DALTsix and Ettan ${ }^{\mathrm{TM}} \mathrm{VE}$ systems (Amersham Biosciences). Two replicates were performed per protein sample.

\section{Protein identification by MALDI-TOF/TOF analysis}

The gels were stained with Coomassie brilliant blue (CBB) G-250 (BioRad). Protein spots were excised by an Ettan Spot Picker (Amersham Biosciences). In-gel digestion was performed as previously described [12]. Protein identification was carried out using MALDITOF/TOF mass spectrometry (4700 MALDI-TOF/TOF mass spectrometer; Applied Biosystems, California, USA). 


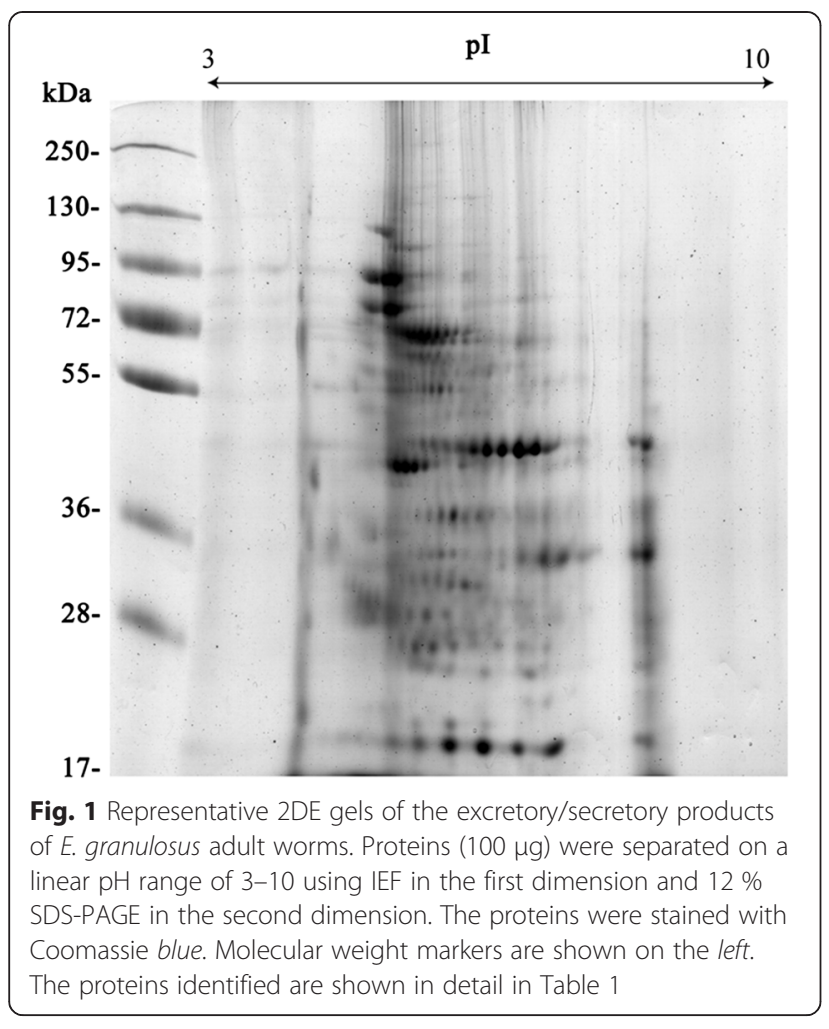

The spectra were processed and analyzed by the Global Protein Server Workstation (GPS; Applied Biosystems), which uses the internal Mascot v2.1 software (Matrix Science, London, UK) to search for peptide mass fingerprints and MS/MS data based on the NCBI nonredundant protein database. Identification with a GPS confidence interval $>95 \%$ was accepted. Gene ontology (GO) terms were applied to the identified proteins; pie charts of the GO terms for molecular functions, cellular components, and biological processes were generated. Additionally, Eukaryotic Orthologous Group (KOG) annotation was assigned (http://genome.jgi.doe.gov/ Tutorial/tutorial/kog.html).

\section{Immunoblot analysis of antigenic proteins}

Adult worm proteins were electro-transferred from the 2DE gels to polyvinylidene fluoride (PVDF) membranes (Amersham Biosciences) at $300 \mathrm{~mA}$ for $2 \mathrm{~h}$ using a TE77 semi-dry transfer unit (Amersham Biosciences). Membranes were blocked for $1 \mathrm{~h}$ in $5 \%$ nonfat milk powder in TBS (20 mM Tris, $500 \mathrm{mM} \mathrm{NaCl}, \mathrm{pH} 7.5$ ) at room temperature and incubated overnight with serum from E. granulosus-infected dogs (1:500 dilution) at $4{ }^{\circ} \mathrm{C}$. After three washes with TBST (TBS containing $0.05 \%$ $\mathrm{v} / \mathrm{v}$ Tween-20), the membranes were incubated at room temperature with HRP-labeled anti-dog IgG (1:10000 dilution; Sigma-Aldrich) for $1 \mathrm{~h}$. Bound antibodies were revealed using the DAB reagent. Antigenic spots on the $2 \mathrm{DE}$ gels were identified based on matches with the $2 \mathrm{DE}$ proteomic map.

\section{Results}

\section{ES products of adult $E$. granulosus}

Approximately 50 spots representative of the ES products were resolved on Coomassie-stained 2DE gels (Fig. 1). A total of 48 spots were subjected to MALDI-TOF/TOF analysis; 33 protein spots corresponding to 8 different proteins were identified (Table 1).

The identified proteins were subjected to functional annotation based on the GO and KOG classification systems. 33,30 , and 20 proteins had GO terms for molecular functions, cellular components, and biological processes, respectively. A summary of the GO and KOG annotations is provided in Fig. 2. Three proteins could not be classified by KOG.

\section{Antigenic proteins of $E$. granulosus adult worms}

To identify adult worm antigenic proteins, we performed 2DE immunoblot analyses using serum from $E$. granulosus-infected dogs. In this study, 36 antigen spots were detected (Fig. 3). Using the corresponding 2DE proteomic map, 21 antigen spots were identified, corresponding to 12 different proteins (Table 2), three of which were identified for the first time: severin,

Table 1 ES products of $E$. granulosus adult worms identified by MALDI-TOF/TOF analysis

\begin{tabular}{|c|c|c|c|c|c|}
\hline Gl number & Protein name & Species & MW & $\mathrm{p} /$ & Protein score C.I.\% \\
\hline 547974 & Paramyosin & E. granulosus & 98681.8 & 5.21 & 100 \\
\hline 262192839 & Enolase & E. granulosus & 46531.9 & 6.48 & 100 \\
\hline 576695773 & Actin & E. granulosus & 41717.8 & 5.3 & 100 \\
\hline 576698524 & Small heat shock protein p36 & E. granulosus & 35821.2 & 5.92 & 99.995 \\
\hline 6016537 & Malate dehydrogenase, cytoplasmic & E. granulosus & 36627.8 & 8.11 & 100 \\
\hline 2316076 & Glutathione S-transferase & E. granulosus & 25536.8 & 7.51 & 100 \\
\hline 189016336 & Thioredoxin peroxidase & E. granulosus & 21419.7 & 5.78 & 100 \\
\hline 31077167 & Cyclophilin & E. granulosus & 17343.4 & 6.41 & 99.003 \\
\hline
\end{tabular}




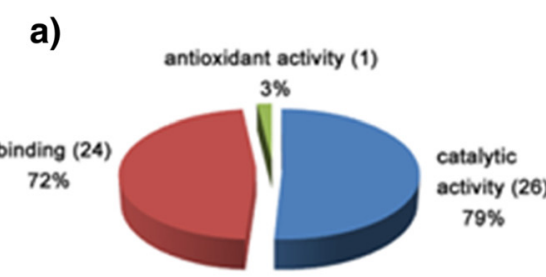

c)

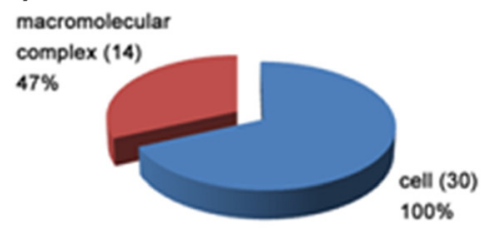

b)

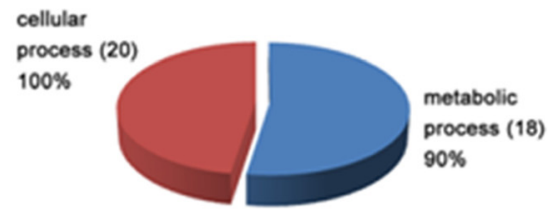

d)

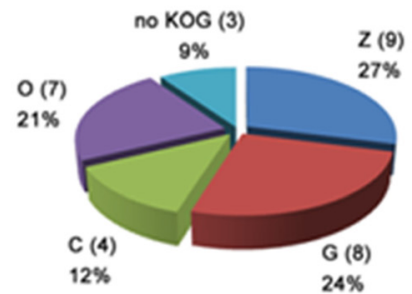

Fig. 2 Functional analysis of the excretory/secretory proteins identified in E. granulosus adult worms. Gene ontology terms for the subcategories molecular function (a), cellular component (b), and biological process (c) were assigned to the proteins identified in the adult worms. KOG functional categories (d) were assigned to the proteins identified in the adult worms. The percentage and number (in parentheses) of proteins identified in each functional category are indicated in each sector. KOG functional categories: (Z) cytoskeleton; (O) posttranslational modification, protein turnover, chaperones; (G) carbohydrate transport and metabolism; (C) energy production and conversion; (noKOG) protein not assigned to any KOG category. The number of proteins in the graph might exceed the total number of identified proteins because some were grouped into more than one functional category

hypothetical protein EGR_06319, and triosephosphate isomerase.

A total of 61 adult worm protein spots corresponding to 26 different proteins were identified (Table 3); 2 of these proteins were identified in E. granulosus adult worms for the first time.

\section{Discussion}

In this study, we performed the first proteomic analysis of ES products from adult E. granulosus. Enolase was the most abundant ES product Enolase has been described as a multifunctional surface protein and an ES product of parasites; it exhibits host-interacting properties and is

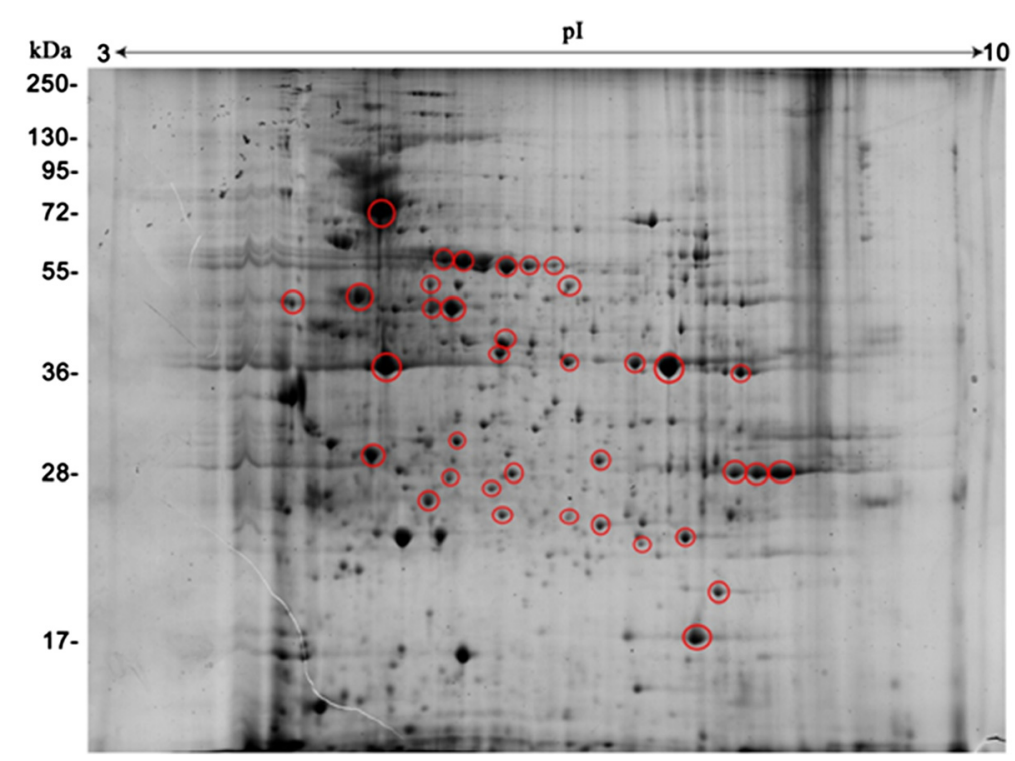

Fig. 3 Antigenic proteins on corresponding representative 2DE gels of the proteins expressed by E. granulosus adult worms. Proteins (800 $\mu \mathrm{g}$ ) were separated on a linear $\mathrm{pH}$ range of 3-10 by using IEF in the first dimension and $12 \%$ SDS-PAGE in the second dimension. Proteins were electrotransferred to PVDF membranes and probed with sera from E. granulosus-infected dogs. Antigenic protein spots are indicated by red circles. Molecular weight markers are shown on the left. The proteins identified are shown in detail in Table 2 
Table 2 Antigenic proteins of $E$. granulosus adult worms identified by immunoblot analysis

\begin{tabular}{|c|c|c|c|c|c|}
\hline Gl number & Protein name & Species & $\mathrm{MW}$ & $\mathrm{pl}$ & Protein score C.I.\% \\
\hline 547974 & Paramyosin & E. granulosus & 98681.8 & 5.21 & 100 \\
\hline 148613837 & Calreticulin & E. granulosus & 42199.2 & 4.47 & 100 \\
\hline 256274460 & HSP60 & E. granulosus & & & \\
\hline 674568928 & HSP70 & E. granulosus & 70640 & 5.47 & 100 \\
\hline 26399708 & Severin $^{a}$ & E. granulosus & 41681.9 & 5.74 & 100 \\
\hline 262192839 & Enolase & E. granulosus & 46531.9 & 6.48 & 100 \\
\hline 576695773 & Actin & E. granulosus & 41717.8 & 5.3 & 100 \\
\hline 576695197 & Hypothetical protein EGR_06319 & E. granulosus & 23119 & 4.77 & 100 \\
\hline 6016537 & Malate dehydrogenase, cytoplasmic & E. granulosus & 36627.8 & 8.11 & 100 \\
\hline 576692880 & Triosephosphate isomerase $^{a}$ & E. granulosus & 27149.8 & 6.6 & 100 \\
\hline 576691284 & Superoxide dismutase & E. granulosus & 15442.8 & 6.15 & 99.992 \\
\hline 31077167 & Cyclophilin & E. granulosus & 17343.4 & 6.41 & 99.003 \\
\hline
\end{tabular}

${ }^{a}$ Antigenic proteins identified for the first time in adult worms are shown in bold

Table 3 Proteins of E. granulosus adult worms identified by MALDI-TOF/TOF analysis

\begin{tabular}{|c|c|c|c|c|c|}
\hline Gl number & Protein name & Species & $\mathrm{MW}$ & $\mathrm{p} /$ & Protein score C.I.\% \\
\hline 547974 & Paramyosin & E. granulosus & 98681.8 & 5.21 & 100 \\
\hline 148613837 & Calreticulin & E. granulosus & 42199.2 & 4.47 & 100 \\
\hline 256274460 & HSP60 & E. granulosus & & & \\
\hline 674568928 & HSP70 & E. granulosus & 70640 & 5.47 & 100 \\
\hline 576695773 & Actin & E. granulosus & 41745.8 & 5.39 & 100 \\
\hline 26399708 & Severin & E. granulosus & 41681.9 & 5.74 & 100 \\
\hline 262192839 & Enolase & E. granulosus & 46531.9 & 6.48 & 100 \\
\hline 576695773 & Actin $^{a}$ & E. granulosus & 41717.8 & 5.3 & 100 \\
\hline 576695197 & Hypothetical protein EGR_06319 & E. granulosus & 23119 & 4.77 & 100 \\
\hline 6016537 & Malate dehydrogenase, cytoplasmic & E. granulosus & 36627.8 & 8.11 & 100 \\
\hline 576692880 & Triosephosphate isomerase & E. granulosus & 27149.8 & 6.6 & 100 \\
\hline 576691284 & Superoxide dismutase & E. granulosus & 15442.8 & 6.15 & 99.992 \\
\hline 31077167 & Cyclophilin & E. granulosus & 17343.4 & 6.41 & 99.003 \\
\hline 29336624 & 78-kDa glucose-regulated protein & E. granulosus & 71876.1 & 5.16 & 100 \\
\hline 674566315 & Transitional endoplasmic reticulum atpase & E. granulosus & 71581.6 & 5.17 & 100 \\
\hline 110558962 & Ferritin & E. granulosus & 16676.2 & 5.24 & 100 \\
\hline 189016336 & Thioredoxin peroxidase & E. granulosus & 21419.7 & 5.78 & 100 \\
\hline 674565853 & Succinate dehydrogenase ubiquinone & E. granulosus & 54812.5 & 7.62 & 100 \\
\hline 576691476 & Transketolase & E. granulosus & 72574.6 & 6.53 & 100 \\
\hline 576693013 & T-complex protein 1 subunit zeta ${ }^{a}$ & E. granulosus & 26703 & 7.77 & 100 \\
\hline 182676451 & Tropomyosin & E. granulosus & 32249.2 & 4.6 & 100 \\
\hline 576698524 & Small heat shock protein p36 & E. granulosus & 35821.2 & 5.92 & 99.995 \\
\hline 674567794 & Oncosphere protein Tso22e & E. granulosus & 31416.3 & 6.61 & 100 \\
\hline 2316076 & Glutathione S-transferase & E. granulosus & 25536.8 & 7.51 & 100 \\
\hline 193213138 & Phosphoglycerate mutase & Chlorobaculum parvum & 28366.6 & 5.76 & 95.745 \\
\hline 576700988 & Fructose-bisphosphate aldolase & E. granulosus & 39702.4 & 8.03 & 100 \\
\hline
\end{tabular}

${ }^{\text {a }}$ roteins identified for the first time in adult worms are shown in bold 
involved in invasion [13-17]. Enolase is likely to play an important role in E. granulosus-host interactions and parasite evasion mechanisms via the immunomodulation of the host immune system. The second most abundant ES product was cyclophilin, which plays a role in parasite development and host-parasite interactions [18]. Furthermore, cyclophilin is a target compound for the immunosuppressive agent, cyclosporine A [19-21].

Actin and paramyosin, cytoskeletal proteins, were other ES products. Similar results have been obtained in other parasites [22-25]. The presence of these proteins may indicate parasite damage or death; however, it is more likely that these proteins are products of tegument shedding. The continuous shedding of the parasite tegument is thought to release components that aid the parasite in evading an effective immune response [26].

An antioxidant defense mechanism is another form of parasite survival. Among the ES products identified, only thioredoxin peroxidase was involved in redox homeostasis. This enzyme plays a major role in protecting the adult worms from oxidative damage. This result is in accordance with the findings of a study performed of hydatid cyst fluid (HCF) that contained ES products from E. granulosus protoscoleces [9].

Metacestodes (hydatid cysts), protoscoleces, and adult worms are different developmental stages of E. granulosus. The HCF is a reservoir of ES products from both the germinal layer and protoscoleces. Compared with HCF [9] and ES products from protoscoleces [11], the ES products from adult worms comprise different proteins. Some of the proteins in this study have not been identified in HCF, including enolase, malate dehydrogenase, GST, and cyclophilin. Similarly, some of the proteins have not been identified in the ES products from protoscoleces, including paramyosin, small HSP p36, and GST. In another study, we observed that the ES products from $E$. granulosus adult worms failed to induce dendritic cell maturation and cytokine production (data not published); this result, however, is in contrast with the finding that HCF induces dendritic cell activation [27]. These differences could be attributed to the different proteins in ES products and HCF; however, this needs to be confirmed.

The search for antigenic proteins by 2DE immunoblots contributed to the identification of 12 parasite proteins that were recognized in the serum of E. granulosus-infected dogs. Nine of these proteins (malate dehydrogenase, HSP60, HSP70, calreticulin, enolase, actin, cyclophilin, paramyosin and superoxide dismutase) were previously identified in E. granulosus and E. multilocularis human infections [9, 18, 28-30]. The other three proteins (severin, hypothetical protein EGR_06319 and triosephosphate isomerase,) were identified in this study for the first time.
Some of these proteins have potential in vaccine development, such as paramyosin. Paramyosins, which are multifunctional modulators of the host immune response, play a role in binding complement components, immunoglobulins, and secreted components of cellular immune response [31-36]. Paramyosin has been proposed by $\mathrm{WHO} / \mathrm{TDR}$ as a vaccine candidate against schistosomiasis and has shown some protection, which may suggest a potential for this protein in the treatment of E. granulosus infections [37-39].

Recently, the protein profile of E. granulosus adult worms has been analyzed by two dimensional LC-MS [40]. In addition to proteins that had been reported in that work, we identified two novel proteins of this parasite, which has increased the known repertoire of the parasitic protein profile and demonstrates the value of our experimental approaches for the proteomic analysis of E. granulosus proteins.

\section{Conclusions}

The present study investigated the ES products and antigenic proteins of E. granulosus adult worms from infected dogs. The results obtained from this study extend the existing proteomic data regarding E. granulosus and could assist in the development of vaccine antigens, drug targets, and immunodiagnostic markers.

\section{Abbreviations \\ 2DE: Ttwo-dimensional polyacrylamide gel electrophoresis; CE: Cystic echinococcosis; ES: Excretory-secretory products; GO: Gene ontology; KOG: Eukaryotic Orthologous Group (KOG); MALDI-TOF/TOF: Tandem matrix-assisted laser desorption/ionization time-of-flight.}

\section{Competing interests}

The authors declare that they have no competing interests.

\section{Authors' contributions}

YW designed the study and experiments, interpreted the experimental data and drafted the manuscript; DX, FZ and $\mathrm{HZ}$ performed the experiments; $\mathrm{XH}$, $X \mathrm{~L}$ and $\mathrm{WW}$ contributed to helminthes collection; YS helped to data analysis; JZ conducted the experiments perform; JC conducted the study design and perform, and delivered the manuscript draft. All authors read and approved the final manuscript.

\section{Acknowledgments}

This work was supported by grants from the National Natural Science Foundation (No. 81371841 to J.C., 81371842 to Y.S.), and the National S \& T Major Program (No.2012ZX10004-201 to J.C.).

\section{Author details}

${ }^{1}$ National Institute of Parasitic Diseases, Chinese Center for Disease Control and Prevention; Laboratory of Parasite and Vector Biology, MOH, China; WHO Collaborating Center for Malaria, Schistosomiasis and Filariasis, Shanghai

200025, China. ${ }^{2}$ Collaborative Innovation Center for Diagnosis and Treatment of Infectious Diseases, State Key Laboratory for Infectious Disease Prevention and Control, National Institute for Communicable Disease Control and Prevention, Chinese Center for Disease Control and Prevention, Beijing 102206, China. ${ }^{3}$ Qinghai Institute for Endemic Disease Prevention and Control, Xining, 811602, China.

Received: 23 November 2014 Accepted: 29 April 2015

Published online: 21 May 2015 


\section{References}

1. Moro P, Schantz PM. Echinococcosis: a review. Int J Infect Dis. 2009;13:125-33.

2. Craig PS, McManus DP, Lightowlers MW, Chabalgoity JA, Garcia HH, Gavidia $\mathrm{CM}$, et al. Prevention and control of cystic echinococcosis. Lancet Infect Dis. 2007;7:385-94

3. Eckert J, Conraths FJ, Tackmann K. Echinococcosis: an emerging or re-emerging zoonosis? Int J Parasitol. 2000;30:1283-94.

4. McManus DP, Zhang W, Li J, Bartley PB. Echinococcosis. Lancet. 2003;362:1295-304.

5. McManus DP. Echinococcosis with particular reference to Southeast Asia. Adv Parasitol. 2010;72:267-303.

6. Casaravilla C, Pittini A, Ruickerl D, Seoane PI, Jenkins SJ, MacDonald AS, et al. Unconventional maturation of dendritic cells induced by particles from the laminated layer of larval Echinococcus granulosus. Infect Immun. 2014:82:3164-76.

7. Nono JK, Pletinckx K, Lutz MB, Brehm K. Excretory/secretory-products of Echinococcus multilocularis larvae induce apoptosis and tolerogenic properties in dendritic cells in vitro. PLoS Negl Trop Dis. 2012;6:e1516.

8. Chemale G, van Rossum AJ, Jefferies JR, Barrett J, Brophy PM, Ferreira HB, et al. Proteomic analysis of the larval stage of the parasite Echinococcus granulosus: Causative agent of cystic hydatid disease. Proteomics. 2003;3:1633-6.

9. Monteiro KM, de Carvalho MO, Zaha A, Ferreira HB. Proteomic analysis of the Echinococcus granulosus metacestode during infection of its intermediate host. Proteomics. 2010;10:1985-99.

10. Aziz A, Zhang W, Li J, Loukas A, McManus DP, Mulvenna J. Proteomic characterization of Echinococcus granulosus hydatid cyst fluid from sheep, cattle and humans. J Proteomics. 2011;74:1560-72.

11. Virginio VG, Monteiro KM, Drumond F, de Carvalho MO, Vargas DM, Zaha A, et al. Excretory/secretory products from in vitro-cultured Echinococcus granulosus protoscoleces. Mol Biochem Parasitol. 2012;183:15-22.

12. Zou Q, Yan X, Li B, Zeng X, Zhou J, Zhang J. Proteome analysis of sorbitol fermentation specific protein in Vibrio cholerae by 2-DE and MS. Proteomics. 2006;6:1848-55.

13. Perez-Sanchez R, Ramajo-Hernandez A, Ramajo-Martin V, Oleaga A. Proteomic analysis of the tegument and excretory-secretory products of adult Schistosoma bovis worms. Proteomics. 2006;6:226-36.

14. Bernal D, de la Rubia JE, Carrasco-Abad AM, Toledo R, Mas-Coma S, Marcilla A Identification of enolase as a plasminogen-binding protein in excretorysecretory products of Fasciola hepatica. FEBS let. 2004;563:203-6.

15. Seweryn E, Pietkiewicz J, Szamborska A, Gamian A. Enolase on the surface of prokaryotic and eukaryotic cells is a receptor for human plasminogen. Postepy Hig Med Dosw. 2007;61:672-82.

16. Ramajo-Hernandez A, Perez-Sanchez R, Ramajo-Martin V, Oleaga A Schistosoma bovis: plasminogen binding in adults and the identification of plasminogen-bingding proteins from the worm tegument. Exp Parasitol. 2007;115:83-91.

17. Antunez K, Anido M, Arredondo D, Evans JD, Zunino P. Paenibacillus larvae enolase as a virulence factor in honeybee larvae infection. Vet Microbiol. 2011;10:83-9.

18. Ortona E, Vaccari S, Margutti P, Delunardo F, Rigano R, Profumo E, et al. Immunological characterization of Echinococcus granulosus cyclophilin, an allergen reactive with $\lg E$ and $\operatorname{lgG} 4$ from patients with cystic echinococcosis. Clin Exp Immunol. 2002;128:124-30.

19. Galat A. Function-dependent clustering of orthologues and paralogues of cyclophilins. Proteins. 2004;56:808-20.

20. Bell A, Monaghan P, Page AP. Peptidyl-prolyl cis-trans isomerases (immunophilins) and their roles in parasite biochemistry, host-parasite interaction and antiparasitic drug action. Int J Parasitol. 2006;36:261-76.

21. Kameyama K, Nishimura M, Punsantsogvoo M, Ibrahim HM, Xuan X, Furuoka $H$, et al. Immunological characterization of Neospora caninum cyclophilin. Parasitology. 2012;139:294-301.

22. Mulvenna J, Sripa B, Brindley PJ, Gorman J, Jones MK, Colgrave ML, et al. The secreted and surface proteomes of adult stage of the carcinogenic human liver fluke Opisthorchis viverrini. Proteomics. 2010;10:1063-78.

23. Kundsen GM, Medzihradszky KF, Lim KC, Hansell E, McKerrow JH. Proteomic analysis of Schistosoma mansoni cercarial secretions. Mol Cell Proteomics. 2005:4:1862-75.

24. Liu F, Cui SJ, Hu W, Feng Z, Wang ZQ, Han ZG. Excretory/secretory proteome of the adult developmental stage of human blood fluke, Schistosoma japonicum. Mol Cell Proteomics. 2009:8:1236-51.
25. Bernal D, Carpena I, Espert AM, De la Rubia JE, Esteban JG, Toledo R, et al. Identification of proteins in excretory/secretory extracts of Echinostoma friedi (Trematoda) from chronic and acute infections. Proteomics. 2006;6:2835-43.

26. Van Hellemond JJ, Retra K, Brouwers JF, van Balkom BW, Yazdanbakhsh M, Shoemaker CB, et al. Functions of the tegument of schistosomes: clues from the proteome and lipidome. Int J Parasitol. 2006;36:691-9.

27. Kanan $\mathrm{JH}$, Chain BM. Modulation of dendritic cell differentiation and cytokine secretion by the hydatid cyst fluid of Echinococcus granulosus. Immunology. 2006;118:271-8.

28. Wang YH, Cheng Z, Lu XF, Tang CT. Echinococcus multilocularis: proteomic analysis of the protoscoleces by two-dimensional electrophoresis and mass spectrometry. Exp Parasitol. 2009;123:162-7.

29. Virginio VG, Hernandez A, Rott MB, Monteiro KM, Zandonai AF, Nieto A, et al. A set of recombinant antigens from Echinococcus granulosus with potential for use in the immunodiagnosis of human cystic hydatid disease. Clin Exp Immunol. 2003;132:309-15.

30. Colebrook AL, Lightowlers MW. Serological reactivity to heat shock protein 70 in patients with hydatid disease. Parasite Immunol. 1997;19:41-6.

31. Gobert GN, McManus DP. Update on paramyosin in parasitic worms. Parasitaol Int. 2005;54:101-7.

32. Wei J, Gu Y, Yang Y, Wang S, Cui S, Zhu X. Identification and characterization of protective epitope of Trichinella spiralis paramyosin. Vaccine. 2011;29:3162-8.

33. Jiz M, Wu HW, Meng R, Pond-Tor S, Reynolds M, Friedman JF, et al. Pilotscale production and characterization of paramyosin, a vaccine candidate for schistosomiasis japonica. Infect Immun. 2008;76:3164-9.

34. Zhao QP, Moon SU, Na BK, Kim SH, Cho SH, Lee HW, et al. Paragonimus westermani: biochemical and immunological characterization of paramyosin. Exp Parasitol. 2007;115:9-18.

35. Park TJ, Kang JM, Na BK, Sohn WM. Molecular cloning and characterization of a paramyosin from Clonorchis sinensis. Korean J Parasitol. 2009:47:359-67.

36. Jiz M, Fridman JF, Leenstra $T$, Jarilla B, Pablo A, Langdon $G$, et al. Immunoglobulin $\mathrm{E}$ (lgE) responses to paramyosin predict resistance to reinfection with Schistosoma japonicum and are attenuated by IgG4. Infect Immun. 2009:77:2051-8.

37. Hemandez MG, Hafalla JC, Acosta LP, Aligui FF, Aligui GD, Ramirez BL, et al. Paramyosin is a major target of the human IgA response against Schistosoma japonicum. Parasite Immunol. 1999;21:641-7.

38. Zhang DM, Pan WQ, Qian L, Duke M, Shen LH, McManus DP. Investigation of recombinant Schistosoma japonicum paramyosin fragments for immunogenicity and vaccine efficacy in mice. Parasite Immunol. 2006;28:77-84

39. Chen $G$, Dai $Y$, Chen J, Wang $X$, Tang B, Zhu $Y$, et al. Oral delivery of the Sj23LHD-GST antigen by Salmonella typhimurium type III secretion system protects against Schistosoma japonicum infection in mice. PLoS Negl Trop Dis. 2011:5:e1313.

40. Cui SJ, Xu LL, Zhang T, Xu M, Yao J, Fang CY, et al. Proteomic characterization of larval and adult developmental stages in Echinococcus granulosus reveals novel insight into host-parasite interactions. J Proteomics. 2013;84:158-75.

\section{Submit your next manuscript to BioMed Central and take full advantage of:}

- Convenient online submission

- Thorough peer review

- No space constraints or color figure charges

- Immediate publication on acceptance

- Inclusion in PubMed, CAS, Scopus and Google Scholar

- Research which is freely available for redistribution 